\title{
HIV/AIDS Clinical Manifestations and their Implication for Patient Clinical Staging in Resource Limited Settings in Tanzania
}

\author{
Idindili Boniphace $^{*, 1,2,3}$, Minzi Omari ${ }^{4}$, Rumisha Susan Fred ${ }^{1,3,5}$, Mugusi Ferdinand ${ }^{6}$ and \\ Tanner Marcel ${ }^{1,3}$
}

\author{
${ }^{1}$ Swiss Tropical and Public Health Institute, Socinstrasse 57, 4002 Basel, Switzerland \\ ${ }^{2}$ Tumbi Region Hospital, P.O. Box 30041 Kibaha, Tanzania \\ ${ }^{3}$ University of Basel, Petersplatz 1, 4002 Basel, Switzerland \\ ${ }^{4}$ Muhimbili University of Health and Allied Sciences, School of Pharmacy, Unit of Pharmacology \& Therapeutics, P.O \\ Box 65013 Dar Es Salaam, Tanzania \\ ${ }^{5}$ National Institute for Medical Research, Tanzania, P.O. Box 9653 Dar Es Salaam, Tanzania \\ ${ }^{6}$ Muhimbili University of Health and Allied Sciences, School of Medicine, Department of Internal Medicine, P.O Box \\ 65000 Dar Es Salaam, Tanzania
}

\begin{abstract}
Background: Tanzania HIV/AIDS management follows WHO clinical staging which requires CD4 counts as complement. Lacking CD4 counts facilities in rural health facilities remains a challenge. Simplified and sensitive clinical staging based on local clinical patterns is useful to ensure effective care without CD4 counts.

Objectives: To assess whether local HIV clinical manifestations can be used to guide HIV management in settings with limited access to CD4 counts in Tanzania.

Methods: A Cross-sectional study conducted at Tumbi and Chalinze health facilities documented clinical manifestations and CD4 counts in 360 HIV/AIDS patients. Simplified management groups comprised of severe and moderate disease were formed based on clinical manifestations and CD4 counts results. Symptoms with high frequency were used to predict severe disease.

Results: Weight loss (48.3\%) and chronic cough (40.8\%) were the most reported manifestations in the study population. More than $50 \%$ of patients presented with CD4 $\leq 200$. Most symptoms were found to be highly sensitive ( $71 \%$ to $93 \%)$ in predicting severe immunosuppression using CD4<200 cut-off point as a 'Gold standard'. Chronic diarrhoea presented in $10.6 \%$, and predicted well severe immunosuppression either alone (OR 1.95, 95\% CI, 0.95-4.22) or in combination (OR $4.21,95 \%$ CI $0.92-19.33$ ) with other symptoms. Basing strictly on WHO clinical staging $30.8 \%$ of patients were detected to be severely immunosuppressed (Stage 4). While using our proposed management categories of severe and moderate immunosuppression $70 \%$ of patients were put into the severe immunosuppression group, consistent with CD4 cut-off count of $\leq 350$.

Conclusions: HIV/AIDS clinics managing large cohorts should develop validated site specific guidelines based on local experiences. Simplified guidelines are useful for resource constrained settings without CD4 counting facilities.
\end{abstract}

Keywords: HIV, AIDS, clinical manifestation, staging, peripheral, Tanzania.

\section{INTRODUCTION}

In sub-Saharan Africa, the transmission of Human Immunodeficiency Virus (HIV-1) occurs mostly through heterosexual contact and the progression to Acquired Immunodeficiency Syndrome (AIDS) and premature death is the reality for people in most poor areas with limited access to Antiretroviral Therapy (ART) [1-3]. HIV disease progresses from an asymptomatic period of variable

*Address correspondence to this author at the Swiss Tropical and Public Health Institute, Socinstrasse 57, 4002 Basel, Switzerland; Tel: +255(0)754 329591; +255222124885;

E-mails: boniphace.idindili@unibas.ch,idindili@yahoo.co.uk duration, through mild symptoms, to severe disease characteristic of cellular immunodeficiency [1].

Human Immunodeficiency Virus clinical presentation is known to be complex since AIDS was described in 1981[2, 3]. HIV can manifest in a variety of ways depending on the organs affected and concurrent infections prevalent in the area. The initial clinical presentation may mimic symptoms of common endemic diseases in that particular region $[4,5]$ However, the severity of manifestation depends on the infected individual's baseline health status. The most significant early manifestation of HIV infection in Africa was marked by slim disease (diarrhoea and wasting); tuberculosis; variety of Opportunistic Infections (OI); weight loss, fever; and dermatological symptoms $[2,5,6]$. With the 
exception of tuberculosis which continues to increase, other AIDS related diseases are declining gradually due to the widespread use of OI drugs.

World Health Organization (WHO) has established a four stage clinical classification system determined by the presence of Opportunistic Infections and other HIV related conditions [7]. This classification tried to incorporate most of the AIDS-defining illnesses occurring in all regions of the world making a global tool for HIV/AIDS patients care and treatment. It has been a very useful tool in Sub Saharan Africa at the introduction of antiretroviral drugs and establishment of HIV/AIDS treatment cohorts [8]. It helped to capture rapid deteriorating patients and initiation of ART in settings with limited diagnostic resources and less trained clinicians.

Antiretroviral drugs are widely available nowadays and continue to be scaled up in remote rural areas of sub Saharan Africa [9, 10]. The aim of rapid scale up is to reach more people living with HIV and AIDS who cannot easily access ART services in urban hospitals. The main challenges to this plausible strategy include availability of qualified health workers and laboratory services to ensure quality care and the monitoring of drug use [11-13]. In addition, most patients including HIV-infected patients in Sub Saharan Africa present late for hospital care and treatment when the disease has advanced [13-15]. By then initial AIDS signs and symptoms might have been treated empirically through self medication or use of herbal medicines. Such remedial actions usually obscure important AIDS clinical features and make it difficult for the attending clinician to solicit signs and symptoms to properly stage the patient.

It is evident that HIV/AIDS patients' management in Sub Saharan Africa continues to be guided primarily by clinical staging [8, 16, 17] owing to the insufficient availability and/or frequent breakdowns of CD4 cells count machines, shortage of qualified medical personnel and laboratory reagents and other logistic issues impair [18]. On the other hand WHO clinical staging depends on a patient presenting signs and symptoms; knowledge and skills of the health care worker to make a definitive staging $[8,17,19]$. Furthermore, WHO clinical staging is less sensitive in identifying patients with CD4 cell counts between 200 -350 cells per $\mu \mathrm{L}$ [4, 20]. Therefore, it fails to identify some patients in need of ART.

Taking into considerations the complexities of HIV clinical manifestation in our setting which often does not match WHO clinical staging. Clinicians in lower health facilities, who are expected to attend to HIV patients in their local settings, need simplified and easy to use clinical staging guidelines developed by utilizing site specific data and clinical experiences. This approach could effectively support management of HIV/AIDS patients in ART cohorts based on site specific experiences. Moreover, the broader availability of ART as well as new approaches to deal with opportunistic infections call for a review of the clinical presentations seen within care and treatment programs in different settings. To date, no studies have proposed simplified HIV/AIDS clinical staging based on local experience. With the inspiration of WHO validated HIV/AIDS clinical definition, our study aimed at developing simplified HIV/AIDS clinical staging system based on data

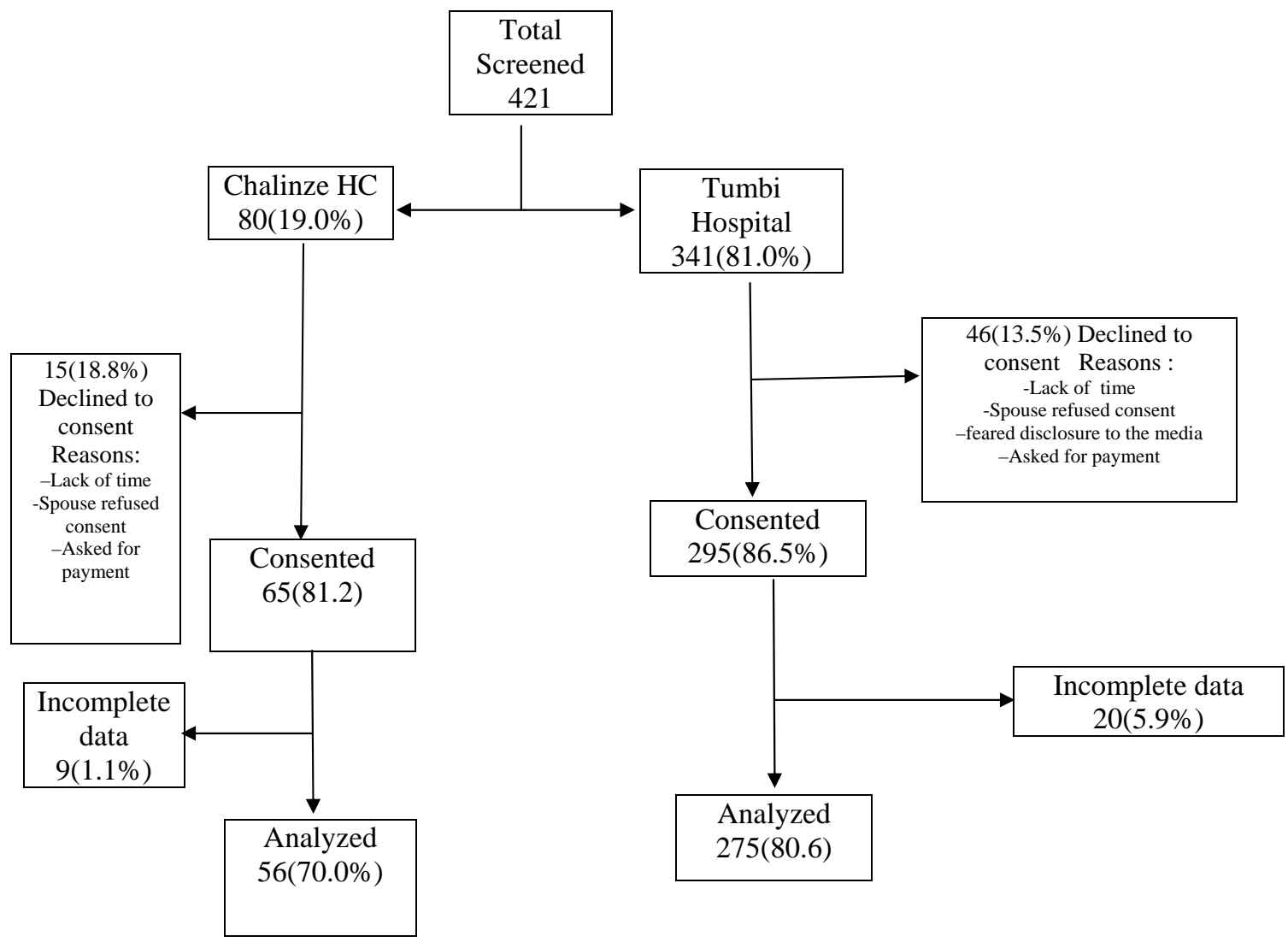

Fig. (1). Patients profile flow chart. 
generated locally from peri-urban and rural health facilities to allow more effective patient management and ART cohorts at peripheral level in the absence of CD4 counts.

\section{METHODS}

\section{Setting and Study Participants}

The study was conducted at Tumbi Regional Hospital and Chalinze Health Centre in Pwani Region, Eastern Tanzania between April and December 2008. Tumbi Regional Hospital is located $40 \mathrm{~km}$ from Dar es Salaam, the commercial capital of Tanzania. The hospital has a bed capacity of 200 beds and serves as a regional referral Hospital. Chalinze Health Centre is located $70 \mathrm{~km}$ from Tumbi Hospital at the junction of the main upcountry highways with HIV prevalence of $15 \%$, while Pwani Region prevalence was $7 \%$. Both health facilities provide services to a mixture of patients from urban and rural villages. Most residents of Chalinze reside in rural villages and generate income from farming and trading of different types of goods.

Tumbi Hospital runs two separate HIV/AIDS clinics for adults and children. At the time of initiation of this study in April 2008, Tumbi Hospital and Chalinze Health Centre had enrolled a total of 3851 and 450 patients to care and treatment, respectively.

We recruited HIV-infected adult patients (age $\geq 15$ years) coming for the first time to register for care and treatment services. The inclusion criteria included; permanent residence to the health facility catchments area; no prior use of ARVs and or co-trimoxazole prophylaxis. A total of 360 female and male patients consented to participate in the study as depicted in the flow chart (Fig. 1). Recruitment of study participants lasted for 3 months.

\section{Data Collection}

Each consenting patient was clinically examined in the standard way that involved a detailed history, physical examination and laboratory tests. Additional laboratory tests depended on the suspected diagnosis. Patients' sociodemographic characteristics and clinical information were recorded in a structured report form in addition to routine patient case report forms.

\section{Laboratory Procedures}

Blood, sputum, urine and stool samples were collected and analyzed. Blood samples were analyzed for CD4 cell counts, HIV-1 P24 plasma ELISA assay, haemoglobin, liver and renal function tests. Blood was collected in EDTA tubes for enumeration of CD4 cells by using FACS count (BD Biosciences, California, USA). Biochemistry and haematological parameters were analyzed using Biochemical analyzer (Italy) and haematological analyzer (Pentra 80, France) respectively. Thick blood smears were Giemsa stained and microscopically examined for Malaria parasitaemia [21]. Sputum specimens were stained using Ziehl-Neelsen technique and examined for mycobacterium tuberculosis [22].

Stool samples were fixed using sodium acetate-acetic acid-formalin (SAF) solution and microscopically examined for intestinal parasites. Part of freshly passed stool was inoculated and cultured in Xylose Lysine Deoxycholate Agar
(XLD) media for Salmonella and Shigella species. A direct microscopic examination was performed on urine samples. This paper focuses on CD4 cell counts results in comparison to the WHO clinical staging.

\section{Data Analysis}

All data was entered into Microsoft ${ }^{\circledR}$ Access, and analyzed using Stata Intercooled version 9.

Each clinical symptom or sign was coded and counted individually to estimate the frequency of occurrences from every patient. About 140 different signs and symptoms were recorded. Then the frequencies were used to estimate the proportion of patients with that particular sign or symptom. Only signs and symptoms with high frequencies were used in this analysis.

We attempted to form two simplified management groups of patients based on either CD4 counts categories or WHO clinical stages. With respect to WHO clinical staging; group one (severe immune suppression) is formed by patients with clinical stages III/IV and group two (moderate immune suppression) is formed by patients with clinical stages I/II. Similarly, when using CD4 cell counts severe immune suppression was defined by patients with CD $4 \leq 200$ cells per $\mu \mathrm{L}$ whilst moderate immune suppression is formed by patients with $\mathrm{CD} 4>200$ cells per $\mu \mathrm{L}$.

We then determined sensitivity, specificity, positive and negative predictive values using CD4 cells count level as the "gold standard". Symptoms or signs individually and in combinations were used to predict severe disease. Only symptoms which had high frequency and troubled the patient for more than two weeks were used.

\section{Ethical Approval}

The study received scientific and ethical approval from the Muhimbili University of Health and Allied Sciences Research Ethics Review Board. Permission was obtained from Region, District and local site authorities. Written informed consent or witnessed verbal consent for participants unable to read or write was obtained from each patient in Kiswahili.

\section{RESULTS}

During the study period $421 \mathrm{HIV}$-infected patients aged 15 to 80 years were recruited to participate in the study, $341(81.0 \%)$ and $80(19.0 \%)$ were from Tumbi hospital and Chalinze health centre, respectively. Sixty one (14.5\%) patients declined to participate due to various reasons (Fig. 1). In total $360(85.5 \%)$ patients were consented, complete data for analysis was recorded from 331 (78.6\%) patients. Twenty nine patients were excluded from the final analysis due to incomplete data, i.e. doubtful CD4 counts results or names, age and sex not corresponding to clinical information. Patients rejected to participate in the study and those excluded from analysis had similar social and demographic characteristics to those finally analyzed.

\section{Socio-Demographic and Clinical Characteristics}

Table 1 summarizes demographic and clinical characteristics of the participants. There were 191(57.7\%) patients in the study with CD4+ T-lymphocytes count of less than 200 cells per $\mu \mathrm{L}$. The median age was comparable in 
Table 1. Demographic and Clinical Characteristics of Patients at First Clinical Assessment Grouped by CD4 Cell Count Categories

\begin{tabular}{|c|c|c|c|c|}
\hline Variable & All Patients (N=331) & $\begin{array}{c}\text { CD4 }>200 \text { Cells per } \mu \mathrm{L} \\
(\mathrm{N}=140)\end{array}$ & $\begin{array}{c}\text { CD4 } \leq 200 \text { Cells per } \mu \mathrm{L} \\
(\mathrm{N}=191)\end{array}$ & p-Value \\
\hline Median age in years(IQR) & $36(12)$ & $36(14)$ & $36(10)$ & \\
\hline $\begin{array}{l}\text { Sex N (\%) } \\
\text { Male } \\
\text { Female }\end{array}$ & $\begin{array}{l}117(35.3) \\
214(64.7)\end{array}$ & $\begin{array}{l}49(35.0) \\
91(65.0)\end{array}$ & $\begin{array}{c}68(35.6) \\
123(64.4)\end{array}$ & $P=0.910$ \\
\hline $\begin{array}{l}\text { Residential status N (\%) } \\
\text { Urban } \\
\text { Rural }\end{array}$ & $\begin{array}{l}108(32.6) \\
223(67.4)\end{array}$ & $\begin{array}{l}47(33.6) \\
93(66.4)\end{array}$ & $\begin{array}{c}61(31.9) \\
130(68.1)\end{array}$ & $P=0.754$ \\
\hline $\begin{array}{l}\text { WHO Clinical stage N (\%) } \\
\text { I } \\
\text { II } \\
\text { III } \\
\text { IV }\end{array}$ & $\begin{array}{l}59(17.8) \\
75(22.7) \\
95(28.7) \\
102(30.8)\end{array}$ & $\begin{array}{l}42(30.0) \\
38(27.1) \\
35(25.0) \\
25(17.9)\end{array}$ & $\begin{array}{l}17(8.9) \\
37(19.4) \\
60(31.4) \\
77(40.3)\end{array}$ & $P=0.0001$ \\
\hline Median CD4+ T- cells per $\mu \mathrm{L}$ (IQR) & $158(253)$ & $377(259)$ & $77.5(99.5)$ & \\
\hline
\end{tabular}

both groups of patients with mild and severe immunosuppression. Most patients 214(64.7\%) were females, and the majority $223(67.4 \%)$ of patients resided in rural areas. Seventeen patients $(8.9 \%)$ and $37(19.4 \%)$ with CD4+ T-lymphocytes below 200 cells per $\mu \mathrm{L}$ were classified with WHO clinical stages I and II, respectively. Similarly, $35(25.0 \%)$ and $25(17.9 \%)$ of patients were staged in clinical stages III and IV, respectively, had CD4+ T-lymphocytes greater than 200 cells per $\mu \mathrm{L}$. The overall median CD4+ Tlymphocytes counts at enrolment was $158($ IQR 253 ) cells per $\mu \mathrm{L}$, with the lowest median (77.5 (IQR 99.5)) in patients with severe immunosuppression.

\section{Patient's Main Presenting Symptoms and Signs at Recruitment}

At presentation to the clinic weight loss of more than 5 $\mathrm{kg}$ was the most frequent $160(48.3 \%)$, followed by chronic cough that persisted for more than 2 weeks 135(40.8\%). Diarrhoea was less common $(10.6 \%)$ in this study population. Recurrent fever was recorded in $132(39.9 \%)$ patients; other symptoms with high frequency included headache 105(31.7\%); Peripheral neuropathy 57(17.2\%) and dizziness $70(21.1 \%)$. Various types of skin diseases were recorded in $34(10.3 \%)$ patients, but Pruritic Papular Eruptions was the most common dermatological condition (Table 2A). Thirty six (11\%) patients presented with genital discharge; $12(33 \%)$ of them had sexually transmitted infections. In addition to major clinical symptoms and signs; $132(37 \%)$ patients presented with mild non-specific various clinical features. Major AIDS-defining Opportunistic Infections diagnosed in this study included: Tuberculosis (15\%); Pneumocystis carinii Pneumonia (7\%); Herpes zoster (5\%); Cryptococcus meningitis (3\%); and Kaposi's sarcoma $(3 \%)$.

Table 2A. Symptoms and Signs for HIV/AIDS Persisting for More than Two Weeks and their Performance to Predict severe Immunosuppression at First Assessment (P-value $\leq$ 0.25)

\begin{tabular}{|c|c|c|c|c|c|c|c|}
\hline \multirow{2}{*}{ Symptom/Sign } & \multirow{2}{*}{$\begin{array}{c}\text { Frequency of } \\
\text { Signs and } \\
\text { Symptoms N } \\
(\%)\end{array}$} & \multicolumn{2}{|c|}{ CD4 $\leq 200$ Cells per $\mu \mathrm{L}$} & \multicolumn{2}{|c|}{$\begin{array}{l}\text { WHO Clinical Stage } \\
\text { III /IV }\end{array}$} & \multirow{2}{*}{$\begin{array}{l}\text { Sensitivity } \\
\text { (\%) }\end{array}$} & \multirow{2}{*}{$\begin{array}{l}\text { Specificity } \\
\text { (\%) }\end{array}$} \\
\hline & & Odds Ratio & CI & $\begin{array}{l}\text { Odds } \\
\text { Ratio }\end{array}$ & CI & & \\
\hline Weight loss $>5 \mathrm{~kg}$ & $160(48.3)$ & 1.39 & $0.89-2.16$ & 2.49 & $1.58-3.95$ & 81 & 46 \\
\hline Cough & $135(40.8)$ & 1.44 & $0.92-2.25$ & 3.28 & $2.02-5.32$ & 82 & 36 \\
\hline Fever & $132(39.9)$ & 1.67 & $1.06-2.63$ & 2.74 & $1.70-4.41$ & 83 & 43 \\
\hline Headache & $105(31.7)$ & 0.96 & $0.60-1.54$ & 1.22 & $0.76-1.97$ & 80 & 60 \\
\hline Dizziness & $70(21.1)$ & 1.53 & $0.88-2.65$ & 1.93 & $1.06-3.43$ & 80 & 46 \\
\hline Peripheral neuropathy & $57(17.2)$ & 1.00 & $0.56-1.79$ & 1.44 & $0.79-2.63$ & 85 & 58 \\
\hline Diarrhoea & $35(10.6)$ & 1.95 & $0.95-4.22$ & 1.55 & $0.73-3.28$ & 84 & 70 \\
\hline Skin diseases & $34(10.3)$ & 1.20 & $0.58-2.50$ & 1.27 & $0.60-2.67$ & 71 & 46 \\
\hline Fungal infection (skin and mucous membranes) & $24(7.3)$ & 1.24 & $0.52-2.92$ & 2.75 & $1.00-7.56$ & 93 & 44 \\
\hline
\end{tabular}


Table 2B. Performance of a Combination of Two Clinical Features in Predicting Severe Immunosuppression (P-value $\leq 0.25)$

\begin{tabular}{|c|c|c|c|c|c|c|c|}
\hline \multirow{2}{*}{$\begin{array}{l}\text { Symptom/Signs } \\
\text { Combinations }\end{array}$} & \multirow{2}{*}{$\begin{array}{c}\text { Frequency of Signs } \\
\text { and Symptoms N } \\
(\%) \\
\end{array}$} & \multicolumn{2}{|c|}{ CD4 $\leq 200$ Cells per $\mu \mathrm{L}$} & \multicolumn{2}{|c|}{$\begin{array}{c}\text { WHO Clinical Stages } \\
\text { III /IV }\end{array}$} & \multirow{2}{*}{$\begin{array}{l}\text { Sensitivity } \\
(\%)\end{array}$} & \multirow{2}{*}{$\begin{array}{l}\text { Specificity } \\
\text { (\%) }\end{array}$} \\
\hline & & Odds Ratio & CI & Odds Ratio & CI & & \\
\hline Cough and fever & $74(22.4)$ & 1.71 & $0.99-2.95$ & 3.39 & $1.82-6.28$ & 84 & 29 \\
\hline Weight loss and cough & $84(25.4)$ & 1.78 & $1.06-2.99$ & 3.79 & $2.11-6.81$ & 86 & 32 \\
\hline Cough and Diarrhoea & $18(5.4)$ & 1.97 & $0.68-5.66$ & 2.48 & $0.8-7.72$ & 92 & 60 \\
\hline Weight loss and fever & $96(29.0)$ & 1.40 & $0.86-2.29$ & 2.64 & $1.55-4.47$ & 85 & 43 \\
\hline Fever and diarrhoea & $24(7.3)$ & 2.32 & $0.89-6.01$ & 2.14 & $0.82-5.55$ & 83 & 50 \\
\hline Weight loss and diarrhoea & $24(7.3)$ & 1.85 & $0.74-4.60$ & 2.14 & $0.82-5.55$ & 88 & 57 \\
\hline Dizziness and diarrhoea & $13(3.9)$ & 4.21 & $0.91-19.33$ & 3.90 & $0.85-17.90$ & 85 & 43 \\
\hline
\end{tabular}

Table 2C. Performance of a Combination of Three Clinical Features in Predicting Severe Immunosuppression (P-value $\leq 0.25)$

\begin{tabular}{|c|c|c|c|c|c|}
\hline \multirow{2}{*}{$\begin{array}{l}\text { Symptom/Signs } \\
\text { Combinations }\end{array}$} & \multirow{2}{*}{$\begin{array}{l}\text { Frequency of } \\
\text { Symptoms and } \\
\text { Signs N }(\%)\end{array}$} & \multicolumn{2}{|c|}{ CD4 $\leq 200$ Cells per $\mu \mathrm{L}$} & \multicolumn{2}{|c|}{ WHO Clinical Stage III/IV } \\
\hline & & Odds Ratio & CI & Odds Ratio & CI \\
\hline Cough, fever, Weight loss $>5 \mathrm{~kg}$ & $61(18.4)$ & 1.79 & $0.99-3.25$ & 3.80 & $1.89-7.62$ \\
\hline Cough, diarrhoea, difficult breathing & $10(3.0)$ & 3.01 & $0.63-14.42$ & 6.36 & $0.79-50.85$ \\
\hline Fever, headache, diarrhoea & $13(3.9)$ & 4.21 & $0.92-19.33$ & 3.90 & $0.85-17.90$ \\
\hline Fever, diarrhoea, Difficult breathing & $12(3.6)$ & 2.25 & $0.60-8.49$ & 3.52 & $0.763-16.37$ \\
\hline Weight loss $>5 \mathrm{~kg}$, headache, diarrhoea & $13(3.9)$ & 4.21 & $0.92-19.33$ & 3.90 & $0.85-17.90$ \\
\hline Weight loss $>5 \mathrm{~kg}$, Difficult breathing poor appetite & $38(11.5)$ & 1.68 & $0.82-3.45$ & 5.19 & $1.97-13.67$ \\
\hline Abdominal pain, Headache, diarrhoea & $13(3.9)$ & 2.52 & $0.68-9.34$ & 2.33 & $0.63-8.64$ \\
\hline Headache, Difficult breathing, poor appetite & $21(6.3)$ & 1.90 & $0.72-5.03$ & 3.06 & $1.00-9.33$ \\
\hline
\end{tabular}

Performance of clinical features to predict severe immunosuppression in comparison to WHO clinical staging Tables 2A, 2B and 2C demonstrate the performance of each AIDS presenting symptom alone or in combination with other symptoms in predicting severe immunosuppression. Patients presenting with diarrhoea for more than two weeks have about double the odds ratio of being severely immunosuppressed. Diarrhoea is an important predictor of severe immunosuppression even when presenting with other symptoms (odds ratio ranging from $1.97(95 \% \mathrm{CI}, 0.68-5.66$ ) to 4.21(0.92-19.33) for two and three combination of symptoms). Chronic cough and weight loss are routinely used to classify patients in stages III and IV (WHO odds ratio of $3.28 \quad(95 \% \mathrm{CI}, \quad 2.02-5.32), \quad 2.49(1.58-3.95)$ respectively), but do not specifically predict severe immunosuppression (CD4 $\leq 200$ odds ratios $1.44(95 \% \mathrm{CI}$, $0.92-2.25)$ and $1.39(95 \% \mathrm{CI}, 0.89-2.16)$, respectively) when presented as individual symptoms. Their performance in predicting severe immunosuppression improves when presented in combination with other HIV/AIDS clinical manifestations (Tables $\mathbf{2 B}$ and $\mathbf{2 C}$ ).

Headache, Dizziness and Peripheral neuropathy were among the most frequent symptoms. These symptoms appear to be highly sensitive (sensitivity $80-85 \%$ ) in predicting severe immunosuppression when used as individual symptoms. Similarly, HIV/AIDS patients presenting with dizziness have about two times the odds of being staged in
WHO clinical stage III/IV (WHO odds ratio $=1.93(95 \% \mathrm{CI}$, 1.06-3.43)). But these are non- specific HIV/AIDS clinical manifestations and poorly predicted severe immunosuppression when compared to CD4 cell counts (CD4 $\leq 200$ odds ratios $0.96(95 \% \mathrm{CI}, 0.60-1.54)$ and $1.53(95 \% \mathrm{CI}, 0.88$ $2.65)$ respectively). The same symptoms when presented in combination with other symptoms such as diarrhoea the probability of predicting severe immunosuppression increases (CD $4 \leq 200$ odds ratio $4.21(95 \% \mathrm{CI}, 0.91-19.33)$ for the combination of dizziness and diarrhoea; and for weight loss, headache and diarrhoea).

Sensitivity of each one or combination of two most frequent symptoms to predict severe disease was between $71 \%$ (Skin disease) and 93\% (Fungal infection); and specificity minimum 29\% (combination of cough and fever) and maximum $70 \%$ (Diarrhoea). Fungal infection carried the highest sensitivity of $93 \%$ with WHO clinical stage III/IV odds ratio of 2.75(1.0-7.56). But, when compared to CD4 cell counts, the $\mathrm{CD} 4 \leq 200$ odds ratio drops to $1.24(0.52$ 2.92).

The combinations of three clinical features resulted in an improved prediction of severe immune suppression. However, adding headache into a combination fever and diarrhoea increased the odds of severe immunosuppression (based on CD4 counts) from 2 to 4 folds. A similar trend is observed when added in a combination of weight loss and 
diarrhoea contrary to difficulty in breathing which behaved differently when added in a combination of cough and diarrhoea and or fever and diarrhoea.

\section{DISCUSSION}

This study attempted to develop and validate HIV clinical staging tailored to a particular geographical and endemic area in comparison to the well established WHOstaging. The clinical profiles of about $34 \%$ of patients were unique and obscured which in turn resulted in WHO staging that was inconsistent with the CD4 cell counts. The majority of the patients presented with clinical features of weight loss (and wasting); chronic cough; and persistent fever for more than 2 weeks. These are common symptoms and signs which were described as early HIV manifestation and significantly were associated with sero-conversion in the first decades of HIV epidemic [23, 24]. We also observed a marked shift in AIDS clinical manifestation from the classical AIDS clinical manifestations [23] which previously was marked by profound weight loss of more than $10 \%$ body weight; chronic diarrhoea and prolonged fever for more than one month to a mixed picture of signs and symptoms [23-25]. Although, our patients had reported weight loss, the weight loss was limited to more than $5 \mathrm{~kg}$ and less than 5\% (data not shown) of their initial body weight. The clinical spectrum seen among the patients in both study sites are quite representative to the overall clinical pictures of the HIV/AIDS patients in the area. The two sites are the only care and treatment centres in the whole area.

Interestingly, only $10.6 \%$ of the patients presented with chronic diarrhoea. This is a marked reduction in occurrence of diarrhoea among HIV/AIDS patients attending care and treatment clinics. Diarrhoea is well known to affect $40 \%$ $80 \%$ HIV infected persons and was also associated with high mortality rates in Sub-Saharan Africa [24, 26, 27]. The reduction in prevalence of diarrhoea in HIV infected people can be explained by the now broader availability of OIs drugs and co-trimoxazole without prescription.

Working at care and treatment centres, we recruited newly diagnosed HIV patients that were all included in the ART cohorts according to the Tanzania National HIV/AIDS control programme guidelines. We expected to record more pre-AIDS signs and symptoms such as generalized lymphadenopathy, Herpes zoster and mucocutaneous lesions. Instead, one third of our patients presented with minor non specific and often no symptoms. Most of these patients had CD4 cell counts less than 200 cells per $\mu \mathrm{L}$. Herpes zoster was diagnosed in $5 \%$ of patients, most of them had CD4 cell counts below 200 cells per $\mu \mathrm{L}$ which is contrary to the common believe that Herpes zoster is a stage II disease. It is a reality in most rural, poor communities to accept a HIV test after suffering for a long time and tried on all kinds of remedies without success. During this time their CD4 cell counts progressively declined.

Most of the known common HIV related opportunistic infections were less frequent than expected in this population despite many patients having CD4 cell counts less than 200 cells per $\mu \mathrm{L}$. It is well established that patients at this level of CD4 cell counts have high risk of AIDS opportunistic infections and AIDS related cancers [28]. Tuberculosis was diagnosed in only $15 \%$ of the patients despite the high frequency of chronic cough and difficulty in breathing. Patients with extra pulmonary tuberculosis and Pneumocystis carinii pneumonia could be missed due to limited respective diagnostic facilities. The diagnosis of these diseases was based on sputum and chest $\mathrm{x}$-ray findings. In routine practice, tuberculosis in HIV-infected patients requires regular screening at every visit because single screening does not exclude latent infection that can flare up in the course of HIV disease progression.

Cryptococcus meningitis and Kaposi's sarcoma were diagnosed in only $3 \%$ of the patients. However, the lower rate of HIV related cancers can be justified by the small sample size of this study. Overall, the different clinical patterns and frequencies of opportunistic infections may largely be due to changed approaches in the clinical management brought forward by (i) the broader availability of ART in combination with the establishment of care and treatment centres as part of the Tanzania National HIV/AIDS control program and (ii) the new approaches to handle prophylactically and therapeutically opportunistic infections also outside the Tanzania National HIV/AIDS control program.

The level of incorrect WHO clinical staging found in this study is almost similar to Ugandan experiences where about $50 \%$ of patients were inappropriately staged [20]. In routine clinical practice $\mathrm{WHO}$ clinical stages determine the direction of HIV/AIDS case management. Patients in clinical stages I and II usually receive long time appointments accompanied by minimum laboratory investigations. While, patients in clinical stages III and IV usually receive clinical and laboratory assessment to determine their eligibility to start ART. Therefore, when a sizable proportion of patients cannot be staged correctly at first contact in ART clinics, the initiation of ART is delayed and higher mortality rates can be expected in the first three months of ART [13].

More than half of our patients were in WHO clinical stages III and IV which was consistent to the number of patients with CD4 cell counts of less than 200 cells per $\mu \mathrm{L}$. This is the reality of late presentation and a challenge to ART programs. Using the cut off point for severe immunosuppression of CD4 cell counts $\leq 200$ cells per $\mu \mathrm{L}$; comparison is more conservative based on the Tanzania Care and Treatment Guidelines [16]. However, if a CD4 cell count of $\leq 350$ cells per $\mu \mathrm{L}$ is taken as cut off for advanced immune depression, then the proportion of patients with severe immune depression reaches about $70 \%$ of all cases seen in this study. Taking into consideration the high proportion of patients presenting late with obscured clinical features to care and treatment for the first time, it appears advantageous to classify patients into severe and moderate immune-suppression. Such an approach simplifies the process of clinical staging and reduces the chances of missed appropriate staging and hence delays in starting ART can be avoided.

In our study, skin diseases and fungal infections of the skin and mucous membranes indicated severe immunosuppression when used clinically to stage patients. However, these symptoms do not strongly predict severe immunodeficiency based on CD4 decline (odds ratio 1.2, $95 \%$ CI, 0.52-2.92). In addition about $75 \%$ of patients with herpes zoster were severely immunosuppressed. Most of the 
symptoms showed high sensitivity in predicting severe immunosuppression which is also an indication of clinicians' adherence to treatment guidelines. When compared to CD4 count levels, there was no consistency. If the combination of three clinical features is used, the probability of predicting severe disease reaches $100 \%$ and is consistent with the decline of CD4 cell counts. High sensitivity with lower specificity further supports this patients' classification because of the vulnerability of HIV patients to opportunistic infections if missed and delayed to receive ART.

Based on these study findings, we then recommend for the local application of the new classification of HIV infected patients into severe and moderate immunosuppression based on duration of clinical manifestations. This classification guided by local clinical experience requires further validation. We recognize the small sample size used in this study as a limitation. However the composition of patients from rural and urban settings implies that the guidelines established can be used at a regional level. Therefore and besides our current own efforts, more studies should be conducted to validate the proposed approach of staging, not only for patients' classification but also for monitoring drug side effects and treatment failure in other geographical and endemic settings.

\section{CONCLUSION}

The broader availability of HIV/AIDS treatment as well as new approaches to deal with opportunistic infections, we call for a review of the clinical presentations seen within care and treatment programs in different settings. Besides applying the WHO clinical staging care and treatment centres that look after large cohorts of HIV and AIDS patients information should also be collected to develop and validate site specific guidelines based on local experiences as shown in this study of which the results are currently being validated in other settings.

\section{ACKNOWLEDGEMENTS}

The authors express their sincere gratitude to all patients; health workers at Care and Treatment clinics; and laboratory staff of Tumbi Hospital and Chalinze health Centre who participated in the study. We also thank Dr Koheleth Winani, and the District Executive Director of Bagamoyo District for granting us permission to use the Hospital and Health centre facilities respectively. Thanks to Dr Boniphace Jullu and Dr Marcel Stöckle for their support for sample analysis and inputs for proposal development. Special thanks go to Ms Margrit Sloui, Ms Ndwaki, Ms Makala M, Mosses R, Mkamba H, Ms Rose and Ms Rehmant for support in reagent logistics, data collection and entry respectively. We also acknowledge the support of the Ifakara Health Institute and of the Swiss Tropical and Public Health Institute for their continuous support at all the stages of this study.

Funding: The study received funding from International Ford Scholarships and the Swiss Tropical and Public Health Institute, an associated institute of the University of Basel.

\section{REFERENCES}

[1] Fauci AS, Pantaleo G, Stanley S, Weissman D. Immunopathogenic mechanisms of HIV infection. Ann Int Med 1996; 124: 654-63.

[2] Piot P, Colebunders R. Clinical manifestations and natural history of HIV infection in adults. Western J Med 1987; 147: 709-12.
[3] Idrisa M, Abdulsalami N. The pathophysiology and clinical manifestations of HIV/AIDS. AIDS in Nigeria. Chpt 6, Harvard University Press 2005; pp. 131-50.

[4] Strecker W, Gurtler L, Schilling M, Binibangili M, Strecker K. Epidemiology and clinical manifestation of HIV infection in northern Zaire. Eur J Epidemiol 1994; 10(1): 95-8.

[5] Holmes CB, Losina E, Walensky RP, Yazdanpanah Y, Freedberg KA. Review of human immunodeficiency virus type 1-related opportunistic infections in sub-Saharan Africa. Clin Infect Dis 2003; 36(5): 652-62.

[6] Grant A. Clinical features of HIV disease in developing countries. Leprosy Rev 2002; 73(2): 197-205.

[7] World Health Organization. Antiretroviral therapy for HIV infection in adults and adolescents in resource-limited settings: towards universal access recommendation for public health approach 2006 revision.

[8] World Health Organization. Interim WHO clinical staging of HIV/AIDS and HIV/AIDS case definitions for Surveillance. Africa Region 2005.

[9] Stringer JS, Zulu I, Levy J, et al. Rapid scale-up of antiretroviral therapy at primary care sites in Zambia: feasibility and early outcomes. JAMA 2006; 296(7): 782-93.

[10] Chien CV. HIV/AIDS Drugs for Sub-Saharan Africa: how do brand and generic supply compare? PLoS One 2007; 2(3): e278.

[11] Mullan F, Frehywot S. Non-physician clinicians in 47 sub-Saharan African countries. Lancet 2007; 370(9605): 2158-63.

[12] Morris MB, Chapula BT, Chi BH, et al. Use of task-shifting to rapidly scale-up HIV treatment services: experiences from Lusaka, Zambia. BMC Health Serv Res 2009; 9; 9: 5.

[13] World Health Organisation: Towards universal access: scaling up priority HIV/AIDS in the health sector. Progress Report 2007.

[14] Isidore S, Mohamadou S, Scho"nenberger AM, Menten J, Boelaert M. Determinants of survival in AIDS patients on antiretroviral therapy in a rural centre in the Far-North Province, Cameroon Tropical Med Int Health 2009: 14(1): 36-43.

[15] Dale MN, Bowmanb D, Susan D, Foster, Godfrey-Faussett P. Patient care seeking barriers and tuberculosis programme reform: a qualitative study. Health Policy 2004; 67: 93-106.

[16] Ministry of Health Tanzania. National AIDS control programme. National Guidelines for the management of HIV and AIDS. $3^{\text {rd }}$ ed. Tanzania: Ministry of Health 2008.

[17] Spacek LA, Gray RH, Wawer MJ, et al. Clinical illness as a marker for initiation of HIV antiretroviral therapy in a rural setting, Rakai, Uganda. Int J STD AIDS 2006; 17(2): 116-20.

[18] Willoughby VR, Sahr F, Russell JB, Gbakima AA. The usefulness of defined clinical features in the diagnosis of HIV/AIDS infection in Sierra Leone. Cell Mol Biol (Noisy-le-grand) 2001; 47(7): 1163 7.

[19] Zachariah R, Ford N, Philips M, et al. Task shifting in HIV/AIDS: opportunities, challenges and proposed actions for sub-Saharan Africa. Trans R Soc Trop Med Hyg 2008; 103(6): 549-58.

[20] Shabbar J, Birungi J, Grosskurth H, et al. Use of WHO clinical stage for assessing patient eligibility to antiretroviral therapy in a routine health service setting in Jinja, Uganda. AIDS Res Ther 2008; $5: 4$.

[21] NCCLS. Laboratory Diagnosis of Blood-Borne Parasitic Diseases. Approved Guideline M15-A. National Committee for Clinical Laboratory Standards, Villanova, PA 2000.

[22] Lennette EH, Balows A, Hausler Jr WJ, Shadomy HJ, Eds. Manual of Clinical Microbiology. 4th ed. Washington, D.C.: American Society for Microbiology 1985.

[23] World Health Organization. AIDS surveillance case definition. At a conference of public health officials including representatives of the Centers for Disease Control (CDC) and World Health Organization (WHO) in, Bangui Central African Republic. Bangui 1985.

[24] Serwadda D, Mugerwa RD, Sewankambo NK, et al. Slim disease: a new disease in Uganda and its association with HTLV-III infection. Lancet 1985; 2(8460): 849-52.

[25] Carswell JW. Clinical manifestations of AIDS in tropical countries Trop Doct 1988; 18(4): 147-50.

[26] Morgan D, Ross A, Mayanja B, Malamba S, Whitworth J . Early manifestations (pre-AIDS) of HIV-1 infection in Uganda. AIDS 1998; 12(6): 591-6. 
[27] Lesbordes JL, McCormick JB, Beuzit Y, et al. Clinical aspects of AIDS in the Central African Republic. Med Trop (Mars) 1985; 45(4): 405-11.

[28] Deuffic-Burban S, Losina E, Wang B, et al. Estimates of opportunistic infection incidence or death within specific CD4 strata in HIV-infected patients in Abidjan, Cote d'Ivoire: impact of alternative methods of CD4 count modelling. Eur J Epidemiol 2007; 22(10): 737-44.

Received: October 7, 2009

Revised: August 25, 2010

Accepted: October 11, 2010

(C) Boniphace et al.; Licensee Bentham Open.

This is an open access article licensed under the terms of the Creative Commons Attribution Non-Commercial License (http:/creativecommons.org/licenses/by-nc/ $3.0 /$ ) which permits unrestricted, non-commercial use, distribution and reproduction in any medium, provided the work is properly cited. 